\title{
Discussion On the Application of Traditional Culture in Physical Education of Primary and Secondary Schools
}

\author{
Guo Xiaoguang \\ Chifeng University \\ Chifeng, China
}

\begin{abstract}
According to the current situation of physical education in primary and secondary schools, this paper puts forward a new physical education mode, which integrates traditional culture into physical education in primary and secondary schools. This paper analyzes the feasibility of integrating traditional culture into physical education, and puts forward the teaching strategies of carrying out physical education content and introducing traditional cultural activities in classroom activities against the background of traditional culture, so as to draw the teaching blueprint for traditional culture going into physical education. Then, in order to provide concrete and practical measures for $P E$ teachers to integrate traditional culture into PE teaching, this paper puts forward specific methods for classroom teaching design. Through this research, it is proved that the integration of traditional culture into physical education teaching doesn't hinder the realization of normal teaching objectives, but can greatly increase students' enthusiasm for learning in physical education, at the same time, students can be influenced by traditional culture.
\end{abstract}

Keywords - traditional culture; primary and secondary schools; physical education; teaching strategies; the teaching design

\section{INTRODUCTION}

Physical education is not only for the purpose of training students' bodies, but also to cultivate students' comprehensive quality. This means that the ideal sports classroom should take physical culture and sports skills and teaching mode, in this teaching mode, students can not only improve exercise capacity, improve physical quality, also accept the consciousness of health, sports culture, sports, sports moral aspects such as education, form the consciousness of physical exercise, improve the body quality, cultivate basic physiological health knowledge, accumulated a certain amount of sports humanities knowledge, to better promote the allround development of students. Traditional culture is the treasure in the cultural heritage of the Chinese nation. The integration of traditional culture into physical education can improve the effectiveness of sports culture infiltration in physical education, which is the implementation of the "people-oriented" teaching concept.

\section{THE FEASIBILITY OF INTEGRATING TRADITIONAL CULTURE INTO PHYSICAL EDUCATION}

\section{A. The connection between traditional culture and sports}

Traditional culture refers to the national culture formed in the long river of civilization evolution, which can reflect the characteristics and styles of a specific nation. It is the sum of all kinds of ideology, culture and ideology. Chinese traditional culture, with Confucian culture as the core and Buddhism, Taoism and other cultural forms, has rich ideological connotation. To be specific, traditional Chinese culture includes traditional literature such as poetry and lyrics, music, dance, drama and other forms of performance, martial arts, lion dance, folk games, traditional skills and other traditional national sports culture and folk culture.

As a kind of social activity which takes physical and intellectual activities as basic means and carries out according to certain organization and purpose, the development of sports cannot be separated from certain social and cultural context, and the realization of sports functions ultimately exerts influences on people through the medium of culture to a large extent. In the context of traditional culture, the whole sports industry and school sports are highly dependent on traditional culture. Martial arts is a well-known example. In ancient times, wushu was a way to defend the enemy's attack and strengthen the body. Nowadays, wushu has become a kind of sports. Through practicing martial arts, people can acquire the strength from body to mind, which is not only related to the feeling brought by martial arts movements to people's body, but also has a great connection with the spirit of " Military forces are to be used only for the maintenance of peace and order" behind martial arts. While learning martial arts, it is also influenced by the spiritual civilization of advocating peace and winning safely represented by martial arts. In addition, when training or competition, martial arts practitioners usually start and end with a set of martial arts etiquette, such as embrace and bow, which is the embodiment of traditional culture's pursuit of comity and harmony. Through entering martial arts this sports activity, can contact the rich cultural expression form, realizes the profound cultural connotation; Through the cultural reflection of sports activities, we can deepen the understanding of the value and significance of sports activities, so as to better promote sports activities. 


\section{B. Characteristics of PE teaching}

The teaching of physical education is quite different from that of other subjects. Physical education has the characteristics of openness, and the classroom teaching of this subject has a variety of training methods. Students usually experience warmup, teacher demonstration, exercise, games and other activities in class. Precisely because of the openness of physical education activities and places, physical education teaching naturally has a relaxed and pleasant atmosphere and a gamification form. In this atmosphere and form, students no longer just sit and listen to the teacher, but also have more opportunities and motivation to interact with teachers and students. Sports game atmosphere and game activities can also easily stimulate students' interest in learning and sports ability. In the process of discussing the integration of traditional culture into physical education, we should not only fully consider the role and characteristics of traditional culture education and edification, but also distinguish the main and secondary, and view the role of traditional culture in physical education from the characteristics of physical education and classroom model.

\section{The possible forms of traditional culture in physical education}

After incorporating traditional culture into physical education, the final classroom effect is directly felt by students, so we should take students' psychological characteristics and physical education as the starting point to explore the possible forms of traditional culture in physical education.

At present, most teachers use jogging or warm-up exercises to help students warm up. However, long-term use of this kind of warm-up method will easily make the class seem monotonous and boring, and students will easily feel bored after repeated day after day. Students' enthusiasm for sports learning and exercise will be discouraged at the beginning of the class. There are a variety of folk games in traditional culture, which are often interesting and easy to learn. Incorporating these games into the class preparation can not only help students warm up, but also arouse their enthusiasm to participate.

Traditional culture also contains a lot of folk stories, many of which can be connected with physical education. For example, teachers can use the taiji map and the stories behind it as the introduction link, so that students can prepare for the curve run by recalling the taiji map. As a result, the interesting and hierarchical sense of teaching activities has been greatly enhanced.

In addition to the folk games and folk stories into the extracurricular sports, teachers can also consider to the introduction of the national traditional sports classroom as relaxing activities, for example, teachers can teach students a simple tai chi moves, help students relieve fatigue, relax muscles, cheerful body and mind, to better teaching activity to the next.

\section{The STRATEGY OF INTEGRATING TRADITIONAL CULTURE INTO PHYSICAL EDUCATION}

\section{A. To carry out teaching contents on the background of traditional culture}

In the physical education class, where traditional culture and physical education are integrated, physical education is still the teaching content. It is still the teaching goal to help students keep fit, improve students' health consciousness and moral character of physical education, which teachers must bear in mind. Therefore, when teachers incorporate traditional culture into physical education, they should not reverse the priority and turn physical education into "traditional culture popularization course". However, in order to help students understand traditional culture, understand the spiritual connotation reflected behind traditional culture, and stimulate students' interest in physical education learning and exercise, teachers can carry out physical education content with traditional culture as the background. For example, traditional culture contains an unyielding enterprise idea, "hold world with virtue" moral value pursuit, the harmonious thought of "harmony between man and nature", and the value concept of fair competition and so on outstanding spiritual pursuit, teachers can put these spiritual heritage through the development of the teaching content, in the process of group activities for sports, for example, the teacher before the event and activities has always emphasized the value concept of fair competition, let the students physical quality is obtained by physical activity.

At the same time, in order to make the teaching content less monotonous and boring, teachers can also put the teaching content in a certain cultural background. For example, when training students to stand in line well and quickly, traditional physical education is used to make students stand in line compulsively, and punish the students who stand badly or not quickly enough. However, students do not understand the significance of such a stand, often have a strong sense of dissatisfaction, and will not follow orders, uniform standards such as serious. Teachers can set up a scene, tell students about the traditional military ceremony of military parade, ask students to recall the military parade scene they have seen, ask students to imagine themselves as one of the soldiers, understand their mood in that scene, and imitate their posture when they parade, correct their attitude.

\section{B. To introduce folk games and traditional national sports into classroom activities}

Folk games come in various forms, such as sandbagthrowing, shuttlecock kicking, fancy rope skipping, eagle and chicken catching, etc. Students are often familiar with these games and even enjoy themselves after class. Traditional ethnic sports include wrestling, archery, dragon dance, swing, walking on stilts and other sports. These sports are also popular among students with their diverse interactive forms and interesting props. Teachers can introduce folk games in classroom activities to stimulate students' interest, and also help students warm up with folk games. For example, the traditional way to warm up in the physical education class is to jog twice around the playground. In the physical education class integrating traditional culture, the teacher can let the 
students warm up in the game of "catching chickens with eagles". In terms of helping students relax their body and mind and stimulating their training motivation, teachers can take traditional sports such as wrestling as a reward activity and tell students that they can carry out these traditional sports after finishing sports such as long jump and track and field. In this way, students retain certain suspense and expectation, and will be more focused into the training. In addition, if conditional word, in order to penetrate the traditional culture in the sports classroom, the teacher can also in open characteristic teaching link, show the dragon dance in class, archery and other traditional sports video for students to understand and appreciate, teachers' ability, can also for the students to a sexual performance, tai chi martial arts, let the students from physical education class feel at ordinary times it is difficult to see the charm of traditional sports.

\section{TEACHING DESIGN OF INCORPORATING TRADITIONAL CULTURE INTO PHYSICAL EDUCATION}

\section{A. To set teaching objectives}

Under the background of the new curriculum reform, more and more physical education teachers realize that physical education cannot only be regarded as the teaching and practice of technical movements, but neglect the comprehensive development of students. Physical education teaching changes the previous teaching concept of "emphasis on teaching and light learning", students' main body of learning is emphasized, students become passive to active, comprehensive ability is greatly improved. In this case, will traditional culture into the teaching of sports, also should fully implement the "based on life", the concept of "improve comprehensive ability", from the perspective of students consider when making the teaching goal, more students for a period of reflection teaching contents be interested, whether students understand some of the purpose and the role of the sports action. Will "in life for this", "improve the comprehensive ability" teaching ideas and into the physical education teaching in combination with traditional culture, should be truly stimulate students interest in use of traditional culture, students physical and mental relaxation, penetrate into the traditional culture essence, as a result, too much into the form of expression of traditional culture, from the student to study the demand of the sports content, seemingly colorful but no for the completion of the teaching goal of no effect of "hollow" approach is not desirable. In short, the traditional culture should conform to the existing physical education teaching content and teaching mode, and play a role in the effectiveness of the realization of curriculum objectives. In addition to the successful completion of teaching objectives, teachers should also do appropriate expansion of traditional sports culture and sports project knowledge, so as to achieve the effect of "icing on the cake" on physical education.

For example, taking the teaching content of "imitating the crawling of animals" as an example, the teacher designs teaching objectives: through the practice of imitating the crawling of animals, the teacher promotes the development of students' body muscles and internal organs, and improves the strength and sensitivity of students' upper and lower limbs. When developing this teaching content, students are often confused about the purpose of doing so, raising the question "what is the meaning of imitating the crawling of animals". In order to explain the possible doubts of students and improve their awareness of physical fitness and physical exercise, teachers can introduce wuqinxi, a traditional Chinese fitness method, to explain some crawling movements for students, so that students can understand that the imitation of crawling movements of animals has its origin in the history of physical exercise in China. In this way, the introduction of wuqinxi helps teachers to decompose and refine the teaching objectives, more effectively improve students' health quality, establish health awareness, and achieve the teaching objectives. Therefore, for each traditional sports cultural activity or knowledge introduced into the physical education class, teachers should think well in advance what kind of help it can play to achieve the teaching goal.

\section{B. To design teaching process}

The teaching design of a complete physical education class often includes the preparation part, the warm-up part, the learning part of the class content, the stabilization emotion restores the body and mind and so on teaching links. Under the PE teaching with classroom teaching content as the main line, teachers should take the realization of teaching content as the goal, but in the teaching part involving traditional culture, they should not distort, distort or oversimplify traditional culture to achieve the purpose of "stimulating students' interest". In other words, as the successor of the traditional culture and the relay, the teacher in each teaching link in the process of design, to achieve the teaching goal, for the purpose, at the same time to shoulder protection and inheritance includes traditional culture spirit and traditional sports project such as the responsibility of the traditional culture, save the rich cultural background, reserve the simple traditional culture as a kind of culture.

For example, some teachers design the learning of martial arts movements in the link of stabilizing emotions and restoring body and mind in class. However, because teachers pay too much attention to the technical level of wushu, they ignore the strength and boldness of wushu movement itself, and even ignore the deep cultural connotation behind wushu, transforming wushu into a gymnastic movement. Due to the low level of understanding, students cannot distinguish the difference between simple movements and martial arts, which is easy to misinterpret this excellent traditional sports activity. In addition, in the face of simple and rough action, students do not get the point, easy to feel boring and bored, relax students body and mind this goal cannot be achieved, the result is not worth the loss.

\section{CONCLUSION}

All in all, due to the characteristics of traditional culture and physical education, it is feasible to incorporate traditional culture into physical education classroom teaching in primary and secondary schools, which can help change the current situation that physical education classroom teaching activities and teaching forms are relatively single, effectively stimulate students' interest, and at the same time realize the inheritance of traditional culture. However, in the process of teaching design, teachers should also pay attention to distinguish between priorities and design teaching activities closely around teaching objectives. At the same time, we should pay attention 
to protecting traditional culture and avoid cutting off the diversity of traditional culture.

\section{REFERENCES}

[1] Li minggang, Guan qin. Analysis on the application of traditional folk sports culture in physical education module teaching in primary and secondary schools [J]. Western quality-oriented education,2016,2(24):273.

[2] Chun-gen liu. Traditional culture in the high school sports teaching penetration research $[\mathrm{A}]$. In the Chinese society of education development strategy innovation education teaching professional committee. Proceedings of 2019 national education teaching innovation and the development of high-end BBS (volume 2) [C]. China's education development strategy to learn education professional committee of innovation of teaching: teaching innovation education professional committee of China education development strategy society, 2019:2.

[3] Liu wen. Research on the teaching model of traditional culture integrating into physical education classes in primary and secondary schools [D]. Ningbo university,2014.

[4] Duan chao. Research on the construction of contemporary inheritance system of Chinese excellent traditional culture [J]. Journal of south central university for nationalities (humanities and social sciences edition),2012,32(02):1-6.

[5] Qin likai, Li Xiaolong, Zhao Xianqing. Reflection and construction of traditional ethnic sports teaching model in colleges and universities from the perspective of cultural inheritance [J]. Journal of Beijing sport university,2013,36(03):113-117.

[6] Pan Lingyun. Discussion on physical education teaching model [D]. Central China normal university,2002. 